\title{
Embedded carbon fiber-reinforced polymer rod in reinforced concrete frame and ultra-high-performance concrete frame joints
}

\author{
Shahnaz Basim ${ }^{1}$. Farzad Hejazi ${ }^{2}$ [ $\cdot$ Raizal Saifulnaz Bin Muhammad Rashid ${ }^{1}$
}

Received: 16 April 2019 / Accepted: 21 November 2019 / Published online: 28 November 2019

(c) The Author(s) 2019

\begin{abstract}
Beam-column joints play an important role in providing lateral stiffness and integrity of frames during dynamic loading such as earthquake. In the high humidity areas, during functioning of the building cracks occur, which leads to the corrosion of the reinforcement due to the environmental exposures. Therefore, one of the main failures mechanism of building during an earthquake is caused by easily yielding of corroded steel reinforcement, which leads to reduce functionality of the frame joints in transferring the loads. This study proposed a new design to reinforce the beam-column joints with embedded carbon fiber-reinforced polymer (CFRP) rods, due to their extremely high strength and stiffness, along with the fact that they will not rust or corrode and very light weight. CFRP rods are used in reinforced concrete (RC) frame and ultra-high-performance concrete (UHPC) frame subjected to dynamic load. The prototype of the proposed design is constructed as frame with conventional concrete and frame with UHPC material to conduct experiments Test as well as numerical analysis to evaluate the performance of the proposed joints under dynamic loads. The results showed improvement in the performance of the frames reinforced with embedded CFRP in joints in terms of lateral load resistance capacity, ductility behaviour, overall stiffness, and failure mechanism.
\end{abstract}

Keywords CFRP · Dynamic load · Ultra-high-performance concrete $\cdot$ Embedded CFRP $\cdot$ Frame $\cdot$ Experiment test · FEM

\section{Introduction}

During earthquake, the initial damage in RC frames occurs in the joints. It should be noted that the joints are also the main component in load transferring and provide stability to the structure. Furthermore, old buildings and structures are vulnerable towards earthquakes due to ageing, even in those structures that are designed based on seismic codes (Esmaeeli et al. 2015). Beam-column joint design is considered to be a complex and challenging task for structural engineers (Vaghani et al. 2015). Moreover, during the building function in the event of such dynamic load, the concrete will crack. Environmental exposures contribute to the corrosion of steel reinforcement, and reducing the effective area of reinforcement (Kumar et al. 2013). Consequently,

Farzad Hejazi

farzad@fhejazi.com

1 Department of Civil Engineering, University Putra Malaysia (UPM), Serdang, Malaysia

2 Housing Research Centre, University Putra Malaysia (UPM), Serdang, Malaysia the strength reduction causes the building to collapse after such dynamic load. Strengthening the joint could possibly minimize the damages and increase the building resistance against dynamic load. As such, this study aims to incorporate composites material carbon fiber-reinforced polymer (CFRP) to reinforce the frames joints against dynamic load. The advantages of composites material are corrosion resistance (Potluri and Ketha 2015) and the utilization of composites' material in strengthening bridges and buildings has been practised broadly in recent decade (Ei-hacha and Rizkalla 2005). In addition, Liu et al. (2019) investigated the de-bonding of CFRP sheets raped around reinforced concrete beams using low-cost piezoceramic sensors.

Moving on, Ha et al. (2013) carried out an experimental research using CFRP bars with hexagonal cross section and CFRP sheets to improve the seismic strength exterior of beam-column joints. The result showed that the ultimate load capacity, ductility, energy dissipation capacity of non-seismic designed increased and flexural cracks decreased. Furthermore, Beydokhty and Shariatmadar (2016) strengthened eight external beam-column joints that were damaged with CFRP sheets. It was observed 
that CFRP sheets improved the seismic capacity of the joints. Apart from that, Wang et al. (2016) evaluated damaged RC frame equipped with CFRP sheet experimentally and numerically. The results demonstrated that the CFRP sheets restored the stiffness, ductility and bearing capacity of the damaged frame to its original undamaged form. Zhou et al. (2019) carried out an experimental test of reinforced concrete beams strengthened with anchored with CFRP anchors under static and cyclic loading.

Moreover, Ohu (2012) investigated an alternative method of using FRP plates as internal reinforcements in concrete beams with regard to ductility/deformability performance. Meanwhile, Quiertant et al. (2012) examined if strengthening RC columns with externally bonded FRP for the flexural fortifying of columns was adequate. The result reflected good ductility performances and there was an increase in the lateral load-carrying capacity. In addition, Nor et al. (2013) explored the use of CFRP as reinforcement in form of strips. Such approach was more temperate compared to wrapping or bars in RC beams. It was reasoned that the CFRP provided the required resistance, quality and behaviour, similar to those reinforced with steel bars. Wang et al. (2019) introduced a new composite column, known as composite concrete column with FRP-confined concrete cores (EFCCC) and carried out experimental and numerical test. Zhang and Xu (2019) used CFRP bars to reinforce concrete frame and was implemented only in the beam and column section. However, a mechanics-based approach has been developed for quantifying the deflection of adhesively plated RC beams (El-Zeadani et al. 2019).

Apart from that, Antonopoulos and Triantafillou (2003) provided a key comprehension of the conduct of RC joints that were reinforced with FRP under recreated seismic load. It was observed that FRP enhanced the stiffness, strength, and energy dissipation of the RC joints. Ghosh (2002) evaluated the effectiveness of Carbon FRP laminates in strengthening and repairing of columns with poor splice under earthquake loading. The result demonstrated that the seismic resistance of the sections was successfully upgraded. Apart from that, Le-Trunget et al. (2010) presented an experimental study utilizing CFRP to increase the shear limit in a nonseismic joints. From the data collected, it was concurred that adding CFRP enhanced the flexibility of the joints. Furthermore, Godat et al. (2012) observed the embedded throughsection (ETS) and concluded that there was an increase in bond strength. In addition, Cheng (2005) evaluated a steelfree FRP-concrete modular system. The framework was a concrete slab without any steel cast on CFRP deck panels that can easily be jointed. Meanwhile, Sharbatdar (2003) incorporated the application of FRP grids as transverse reinforcement and FRP bars as longitudinal reinforcement in beams and columns.
Moving on, Kim (2006) evaluated a nonlinear prestressed concrete beam that was strengthened by pre-stressed CFRP sheets. This included experimental validation. The results demonstrated an increase in load-carrying capacity, failure mode, ductility, and cracking behaviour. Moreover, CFRP was used to reinforce not only beam, column, and joints, as Erol et al. (2008) observed the strengthening of masonry infill walls of ineffectively planned RC frame with CFRP and the commitment of CFRP on infill walls. It was concluded that reinforcing infill walls with CFRP increased the lateral load capacity and stiffness of the specimens. Meanwhile, CFRP materials were not limited only to beam, column, and joints as Bischof et al. (2014) demonstrated that retrofitted masonry walls with CFRP sheets in staticcyclic shear tests improved the resistance and deformability of the wall. Apart from that, CFRP can also be used in ultrahigh-performance concrete (UHPC), in addition to conventional concrete. UHPC has higher compressive and tensile strengths compared to conventional concrete.

Furthermore, Çopur et al. (2013) investigated the behaviour of UHPC columns wrapped with axially loaded CFRP. The test results demonstrated that CFRP wrap increased the ultimate strength and strain of the UHPC columns. Moreover, Mutsuyoshi et al. (2011) presented their experiment on the flexural behaviour of hybrid CFRP (HFRP) beams and composite beams that consisted of HFRP beams and concrete topping slab-ultra-high-performance fiber-reinforced concrete (UHPFRC). It was observed that UHPFRC slab increased structural stiffness and strength. In addition, the application of CFRP in concrete structures demonstrated good performance in terms of load resistance, stiffness, and energy dispassion. Moreover, Qin et al. (2019) used FRP in concrete columns with interfacial defects and an experimental test was conducted to determine the interfacial defect on structural performance. Dan et al. (2018) carried out an experimental test on a single story RC frames using CFRP sheets as a strengthening method and the result showed an increase of resistance and stiffness. The used of CFRP is not limited to beam, column, and joints as Zhang et al. (2018) found that CFRP composite was more effective than the aluminum panel in reducing radiation-induced pressure in used in spacecraft applications.

The main motivation of this study is to reinforce concrete beam-column joints with embedded CFRP. Moreover, CFRP is a corrosion-resistant material which is suitable in humid areas. However, most of damages in the frame joints are occurred due to lateral force excitations such as seismic load or cyclic load. Embedded CFRP bars were used in non-seismic design frames subjected to cyclic load using dynamic actuator with $300 \mathrm{kN}$ load capacity. Experimental test and numerical test were carried out to evaluate the performance of embedded CFRP joints in conventional concrete and UHPC frame. 


\section{Proposed design for beam column joints}

The behaviour of non-seismic-reinforced concrete frame systems in recent earthquakes has reflected an inadequate performance of the beam-column joints that are responsible in sustaining damages caused by lateral dynamic load. To enhance load capacity, shear strength and flexibility of the joints when exerted with dynamic load, a new design of beam-column joints was proposed. This was to overcome non-seismic beam-column joints weaknesses through the implementation of embedded CFRP in frame beam-column joints. Furthermore, CFRP is known to possess high strength-to-weight ratio, is rigid and able to increase the load capacity of a structure. In addition, CFRP has high elasticity modulus and strength compared to steel and it is able to enhance the shear strength of reinforced concrete.

Therefore, in this study, the response of conventional and UHPC concrete with embedded CFRP rod in the beam-column joint under lateral cyclic load has been investigated and experimentally tested under normal environment condition, since it is assumed that there is no any corrosion effect due to high humidity environment in CFRP rods.

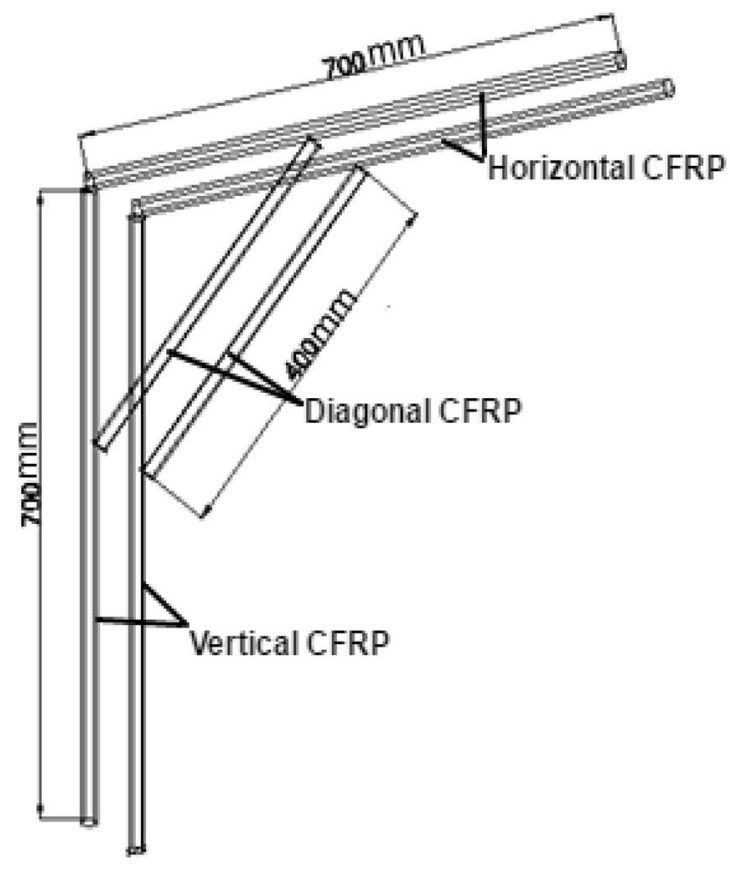

(a)

\section{Embedded CFRP in beam-column design specifications}

A pair of designed CFRP were used in all the joints of the frames. The length of CFRP is considered $700 \mathrm{~mm}$ horizontally, $700 \mathrm{~mm}$ vertically and $400 \mathrm{~mm}$ diagonally, as shown in Fig. 1. The suitable length of CFRP was determined through numerical simulation of bare $\mathrm{RC}$ frame and experimental testing on bare $\mathrm{RC}$ frame subjected to lateral load to identify the location of the weakest parts of the frame joints. Thus, the length of CFRP is determined based on high stress and damaged zones of concrete sections under applied loads.

The designed CFRP were incorporated in two frames with different concrete types. The first frame was an RC frame with embedded CFRP (RC-CFRP) and with concrete compressive strength of $50 \mathrm{MPa}$. The second frame was UHPC and was equipped with embedded CFRP in joints (BUCFRP). The compressive strength for UHPC was $170 \mathrm{MPa}$ based on cube testing results for 28 days. In addition, the frames were casted into moulds of the same cross-sectional area, width, and height, as shown in Figs. 2 and 3. In addition, the CFRP installation in the frames joints is shown in Fig. 4. Furthermore, the properties of steel and CFRP are shown in Tables 1 and 2. These parameters are provided by material manufactures and effective parameters such as

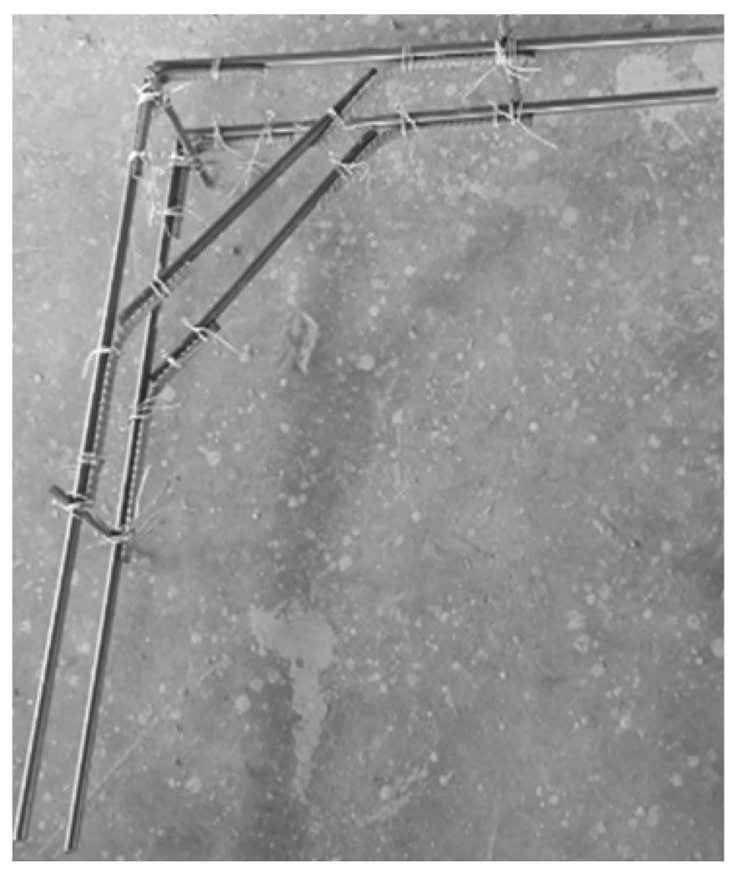

(b)

Fig. 1 Pair of CFRP: a CFRP configuration, b CFRP configuration in lab 


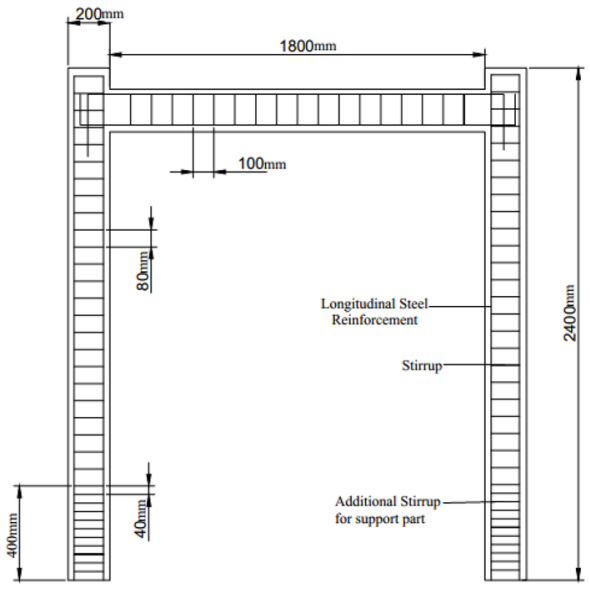

(a)
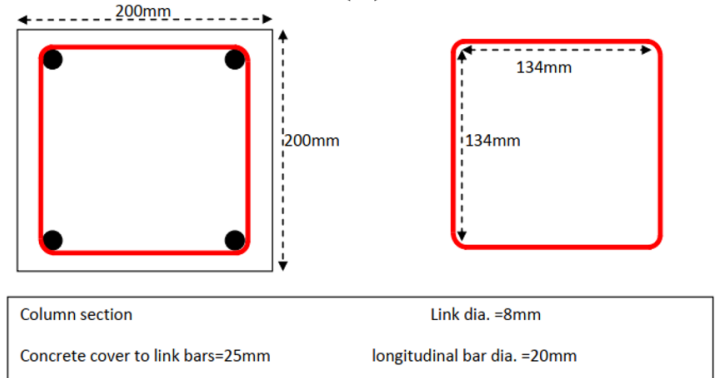

(c)

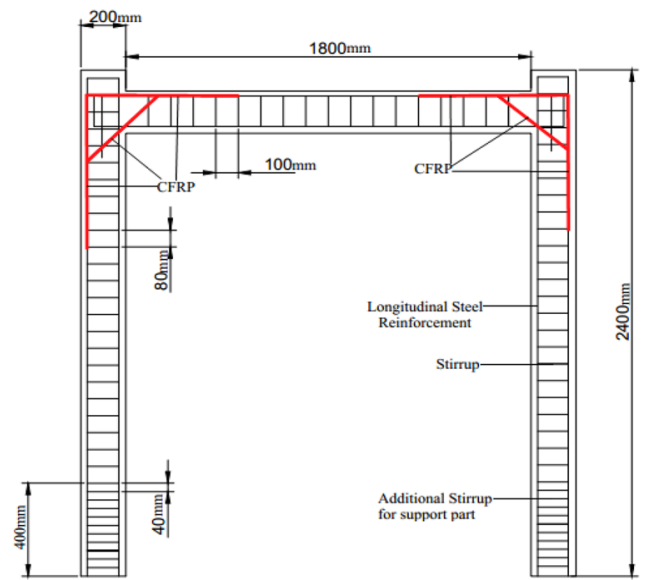

(b)
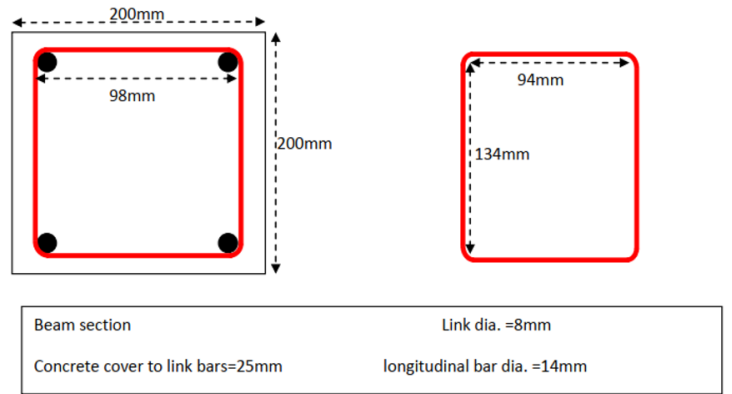

(d)

Fig. 2 Dimension of: a RCF frame, $\mathbf{b}$ RC-CFRP frame, $\mathbf{c}$ column size, $\mathbf{d}$ beam size

Fig. 3 Dimension of: a UHF frame, b BU-CFRP frame

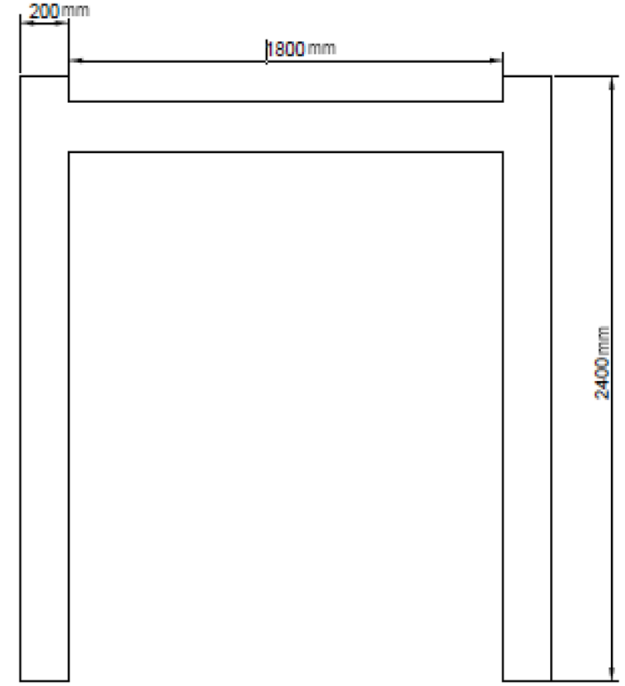

(a)

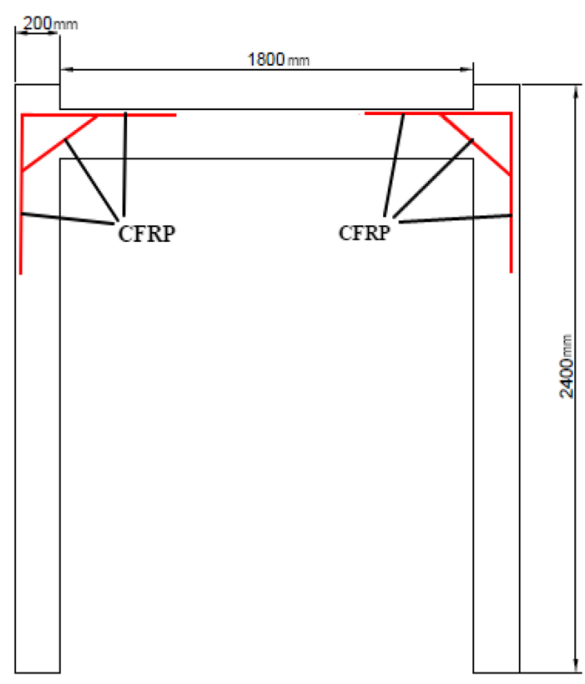

(b) module of elasticity which highly effects the analysis results, and the samples of CFRP and steel bar are tested using universal tensile machine for calibration of material properties.

\section{Experimental procedure}

The objective of the experiment was to assess the design parameters that influenced the strength and behaviour of 


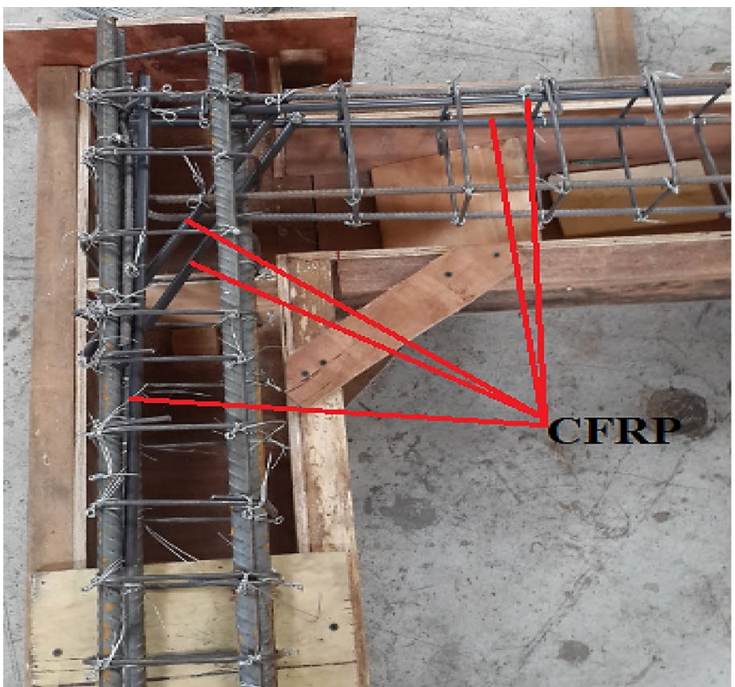

(a)

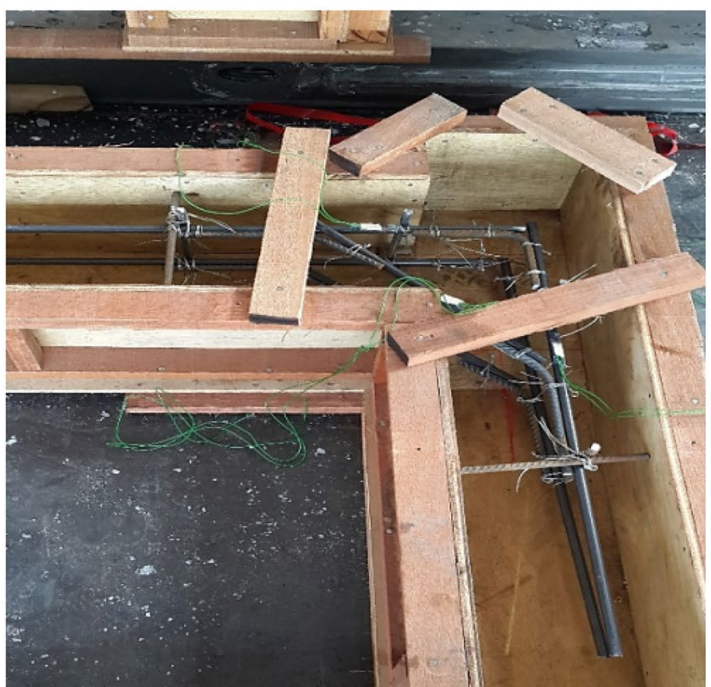

(b)

Fig. 4 CFRP installation in: a CFRP installation in RC-CFRP, $\mathbf{b}$ CFRP installation in UHPC frame

Table 1 Steel properties

\begin{tabular}{ll}
\hline Mass density of steel & $7.83 \mathrm{E}-09$ \\
Young's modulus & 207,000 \\
Poisson's ratio & 0.3 \\
\hline
\end{tabular}

Table 2 CFRP property

\begin{tabular}{ll}
\hline Matrix & Epoxy resin \\
\hline Appearance and colour & Solid, round, black \\
Density $\left(\mathrm{g} / \mathrm{cm}^{3}\right)$ & 1.54 \\
Fiber content $(\%)$ & 71 \\
Cross-sectional area $\left(\mathrm{mm}^{2}\right)$ & 73.9 \\
Diameter $(\mathrm{mm})$ & 9.7 \\
Tensile strength $\left(\mathrm{N} / \mathrm{mm}^{2}\right)$ & 2000 \\
Modulus of elasticity $\left(\mathrm{N} / \mathrm{mm}^{2}\right)$ & 155,000 \\
Shear strength (pa) & 75 \\
\hline
\end{tabular}

CFRP in joints under dynamic load, as shown in Fig. 5. All specimens were subjected to lateral dynamic loads that were applied through dynamic actuator. Moreover, the actuator was powered with hydraulic power supply. The crack patterns were marked and photographed after each increment. The experiment was conducted in University Putra Malaysia (UPM) structure lab in Malaysia. The testing facility was built with reinforced concrete floor and fixed base plate for rigid support and equipped with Shimadzu dynamic Actuator with $300 \mathrm{kN}$ load capacity, Kyowa dynamic data logger, $67 \mathrm{~mm}$ Kyowa strain gauges.
The monotonic displacement history applied to the frames, as shown in Fig. 6. The patterns of displacement history are basically in the cyclic trend with progressively increasing amplitudes based on guidelines for cyclic test on moment frame with three cycles for each displacement amplitude (ATC 1996). The amplitude increments commenced from $2.5 \mathrm{~mm}$ and increased gradually by $5 \mathrm{~mm}$ neither too large nor small up to frame failure occurred.

\section{Experimental result}

The performance of the embedded CFRP in RC frame and UHPC frame joints was evaluated through experimental testing. The frames were casted and tested in the same experimental situation and the result was compared through force-displacement relationship.

\section{Result of cyclic dynamic experiment on RCF and RC-CFRP}

There were initial cracks at the column cross section once the load reached $20 \mathrm{kN}$ for bare RC frame. Furthermore, shear cracks in the joint zone and bending cracks in the beam plastic hinge region appeared, as illustrated in Figs. 7 and 8. In addition, failure took place when the concrete near the beam-column connection began to crush and the concrete cover started to crumble.

Moving on, the maximum capacity of the RCF was $63 \mathrm{kN}$ with maximum displacement of $90 \mathrm{~mm}$. Cracks pattern observed on the RC-CFRP frame under cyclic load and initial bending cracker was observed when the load 


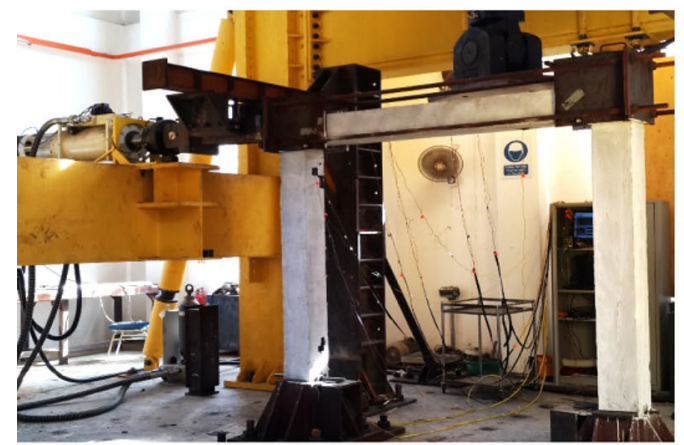

(a)

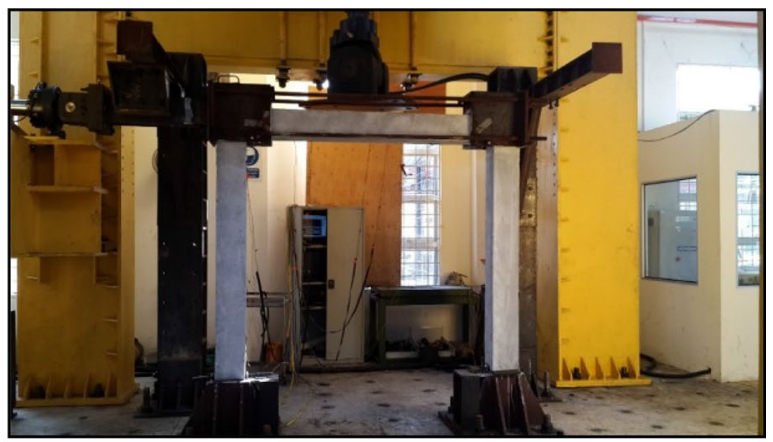

(b)

Fig. 5 Test setup: a frame with actuator on the left, $\mathbf{b}$ frame setup

Fig. 6 Cyclic time history displacement (ATC 1996)

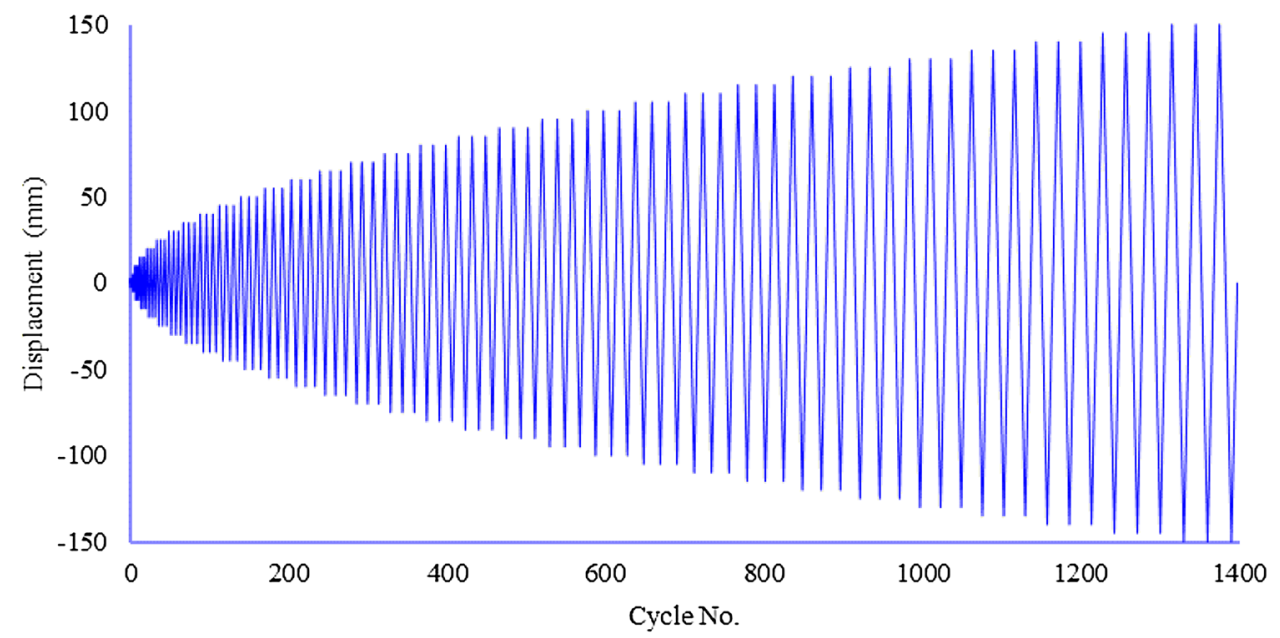

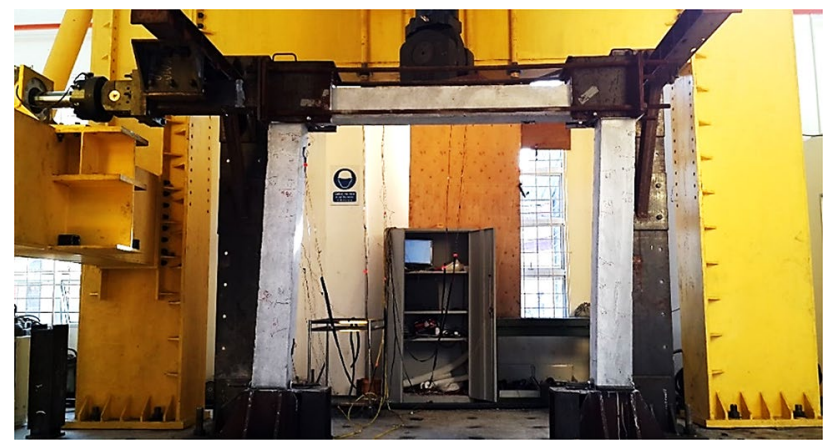

Fig. 7 Deformed frame

reached $32 \mathrm{kN}$. The cracks were distributed around the column cross section together with fine hairline cracks. After reaching the maximum load, shear crack was observed, as shown in Fig. 9. Nonetheless, the declination of strength during cyclic load reversals was not as significant as RCF specimen. This was because the RC-CFRP frame was reinforced with embedded CFRP at the joints. Furthermore, the

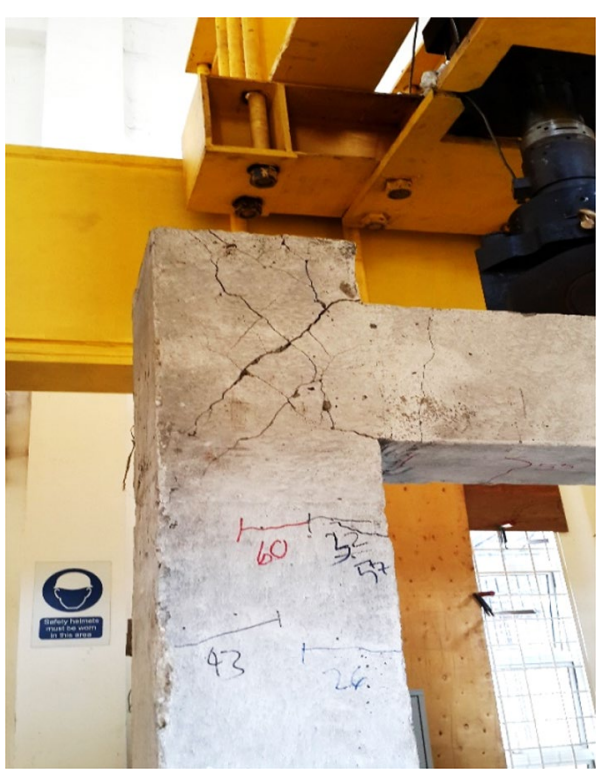

Fig. 8 Crack pattern on RCF 


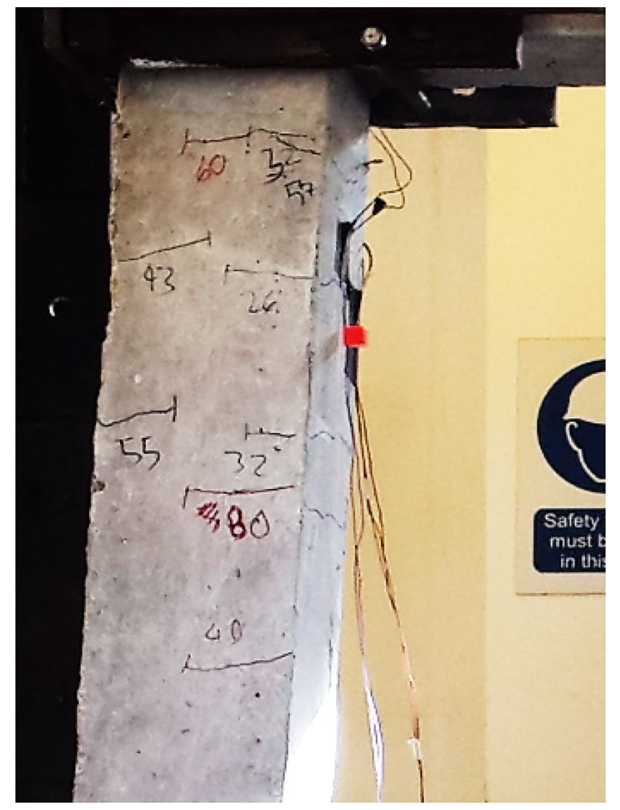

Fig. 9 Crack pattern on RC-CFRP

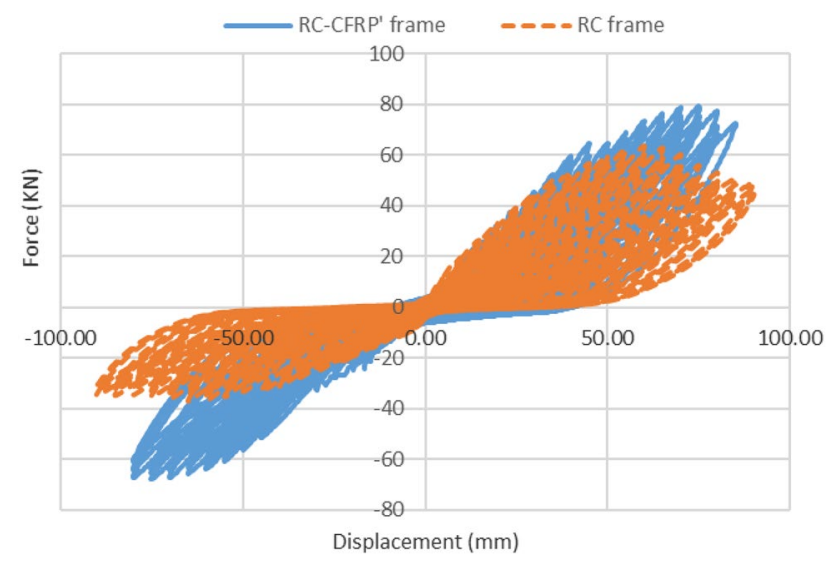

Fig. 10 Comparison between RCF and RC-CFRP hysteresis loop

maximum load capacity of RC-CFRP frame was $80 \mathrm{kN}$ with maximum displacement of $85 \mathrm{~mm}$. During the experimental test, sliding occurred at the frame supports. This caused the loop to jump to high load. Figure 10 shows the compression between bare RC frame and a frame with embedded CFRP in the joints. It was observed that the load capacity of RC-CFRP increased by $26 \%$. Similar observation can be made with regard to the displacement. In addition, CFRP implementation enhanced the overall capacity and flexibility of RC frame.

\section{Result of cyclic dynamic experimental test for UHF and BU-CFRP}

The initial tensile crack for UHF was due to bending at the upper zone of the column. This was caused by the bending of bare UHF frame when the load reached $20 \mathrm{kN}$. At the moment, diagonal shear cracks were observed on the column and the beam section. In addition, the crack width near the joint widened and bending cracks were propagated into the joints, as shown in Fig. 11. Furthermore, at the maximum load of $55 \mathrm{kN}$, the diagonal shear cracks width was more than $4 \mathrm{~mm}$. The joint also began to crush and the concrete cover fall over.

The initial crack for BU-CFRP frame was observed after reaching $25 \mathrm{kN}$. The cracks were concentrated around the upper part of the column. In addition, the bending cracks width near the joints expanded at the maximum load of $61 \mathrm{kN}$ and shear cracks were observed. The width and the number of cracks in the CFRP frame specimen were less than the bare frame. This was because the embedded CFRP helped to increase the integrity of the joint. The crack patterns are shown in Fig. 12.

It should be noted that the maximum load capacity of UHF was $55 \mathrm{kN}$ and the maximum displacement was $60 \mathrm{~mm}$. In addition, it was observed from the hysteresis loop that the loop was not symmetric due to the occurrence of sliding in the supports. Apart from that, the maximum load capacity for BU-CFRP was $61 \mathrm{kN}$ with maximum displacement of $57 \mathrm{~mm}$. Compression between UHF and BU-CFRP hysteresis loop is presented in Fig. 13. The results indicated that UHPC was fairly incapable to withhold lateral load, especially seismic load. Nevertheless, the embedded CFRP bars in BU-CFRP specimen increased the lateral load resistance by $11 \%$. Hence, CFRP improved the UHPC maximum load capacity and the flexibility of the frame joints against lateral load.

\section{Ductility, stiffness, and energy dispassion}

Figure 14 compares RCF and RC-CFRP skeleton graph. It is worth noting that embedded CFRP bars in the beam-column joints increased the ductility of RC-CFRP by $10 \%$ and stiffness by $32 \%$. Furthermore, energy dispassion increased by $111 \%$ for frame with CFRP in the joints, as shown in Table 3.

Figure 15 demonstrates the skeleton graph for UHF and BU-CFRP, as mentioned earlier. The result showed that UHPC frame was fairly weak against lateral load. Nevertheless, the embedded CFRP in the joints increased the lateral load resistance. It also improved ductility by $78 \%$ and stiffness by $11 \%$. In addition, energy dispassion also increased 
Fig. 11 Cracks pattern for UHF: a deep cracks around the joint, b cracks on the column

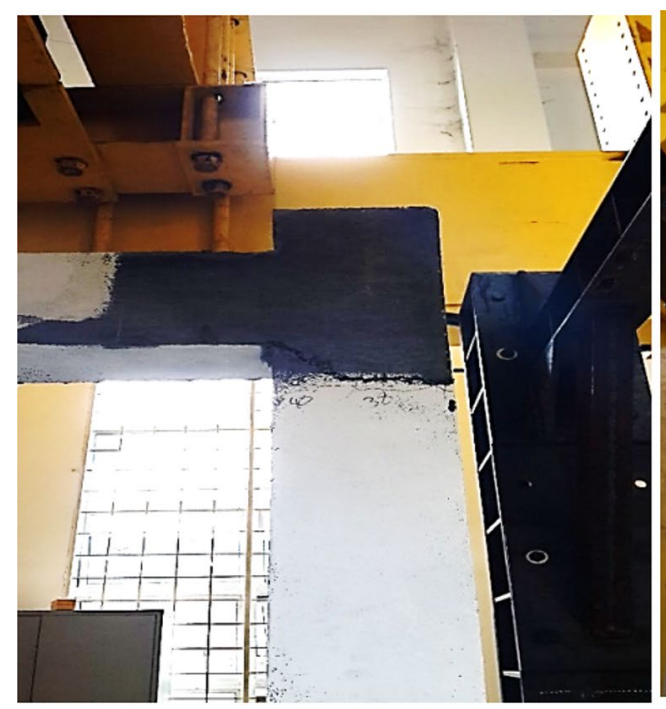

(a)

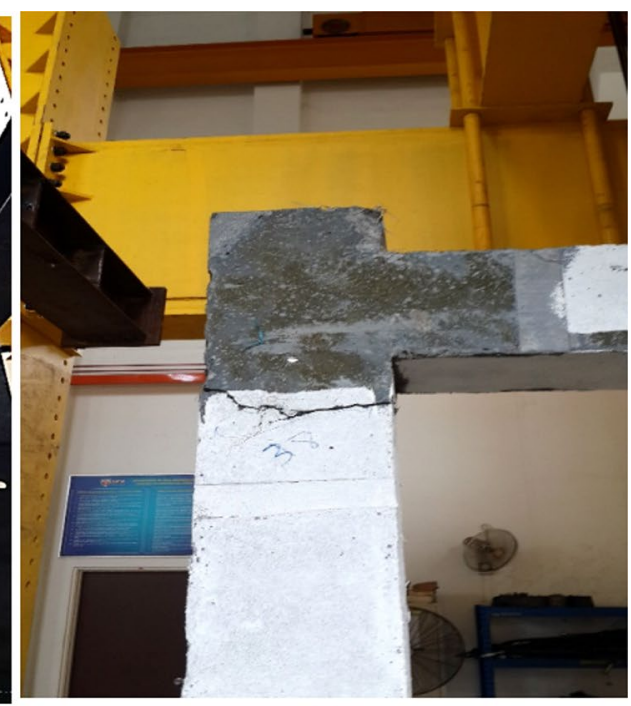

(b)
Fig. 12 Crack patron for BUCFRP: a cracks around the beam, $\mathbf{b}$ cracks on the joint

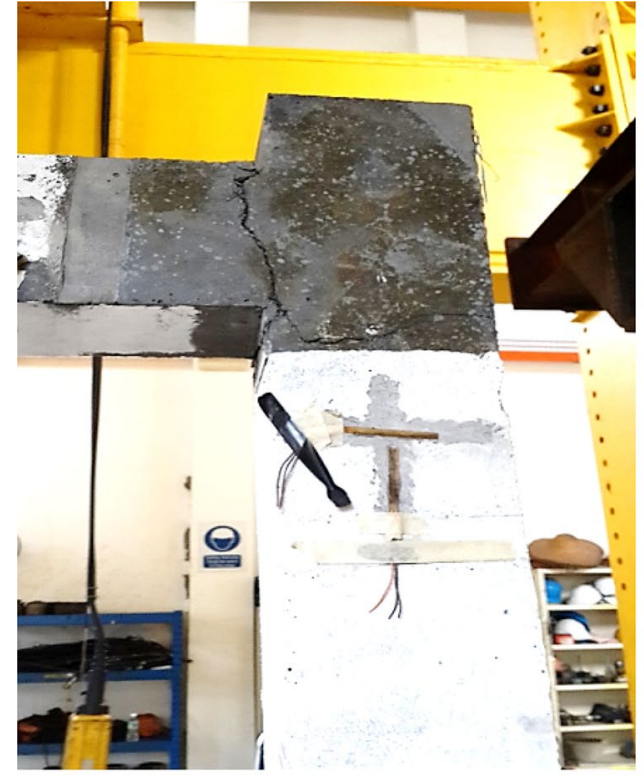

(a)

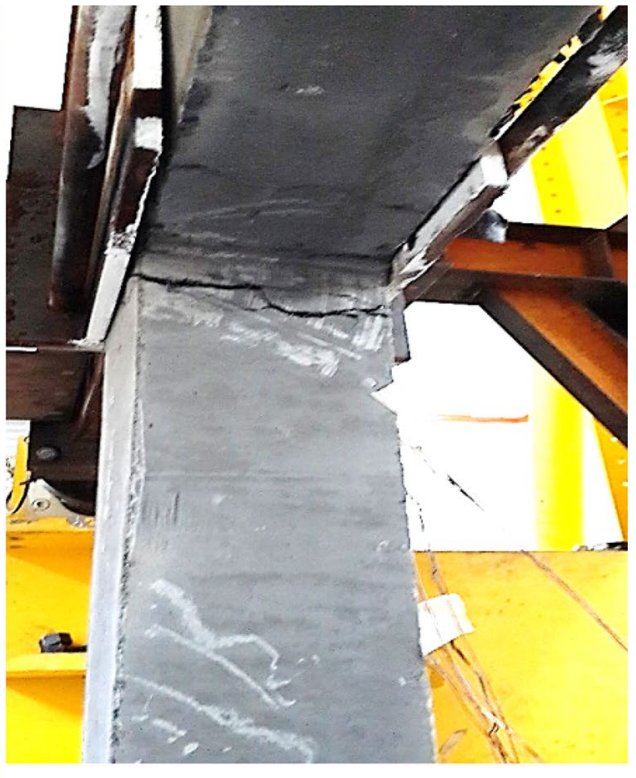

(b)

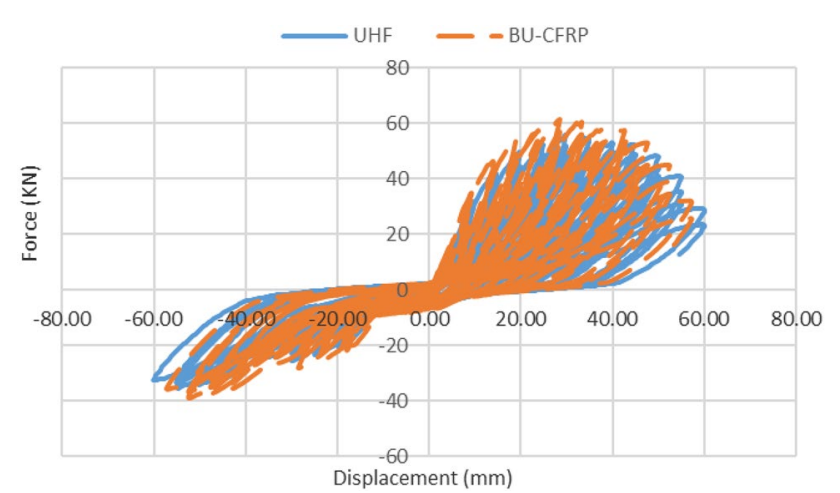

Fig. 13 Comparison between UHF and BU-CFRP hysteresis loop

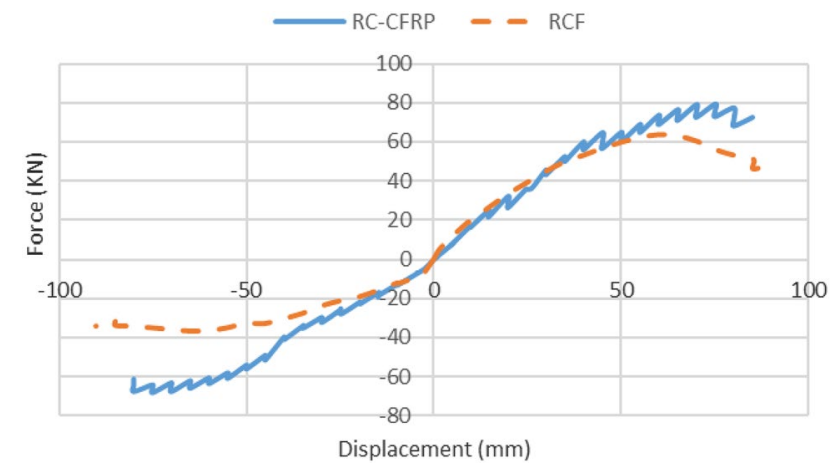

Fig. 14 RCF and RC-CFRP Skeleton graph 
Table 3 Comparison between $\mathrm{RCF}$ and RC-CFRP

\begin{tabular}{llllll}
\hline Frame label & Max force $(\mathrm{kN})$ & $\begin{array}{l}\text { Max displace- } \\
\text { ment }(\mathrm{mm})\end{array}$ & Ductility & Stiffness & Energy dissipation \\
\hline RCF & 63 & 90 & 1.9 & 0.7 & $126,167.2$ \\
RC-CFRP & 80 & 85 & 2.1 & 0.94 & $152,743.1$ \\
Increase $(\%)$ & $26 \%$ & $5.50 \%$ & $10 \%$ & $32 \%$ & $111 \%$ \\
\hline
\end{tabular}

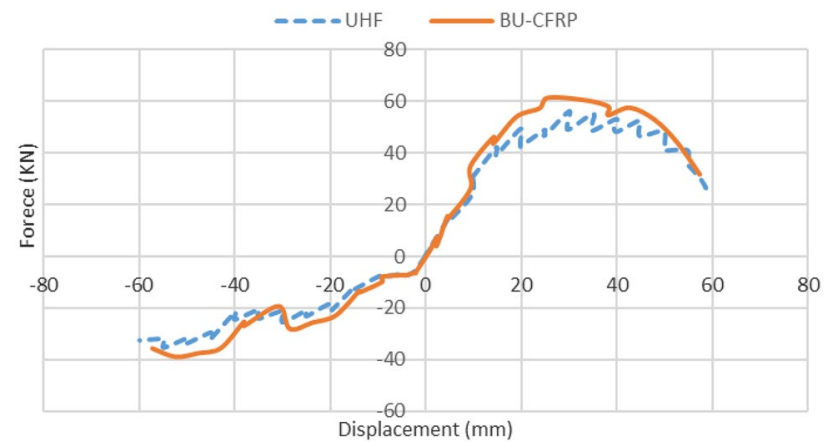

Fig. 15 UHF and BU-CFRP skeleton graph

by $4.8 \%$ compared to UHPC without CFRP, as presented in Table 4.

As mentioned before, the frame subjected to cyclic displacement according to ATC (1996) with three cycles for each displacement magnitude. Therefore, the lateral resistant capacity of the frame is reduced in two consequence cycles after the first cycle in each displacement magnitude. Therefore, during conducting experimental test, the resistant force in two consequence cycles for each displacement amount after the first cycle is reduced which led to variation in the skeleton curve.

The carbon fibers are not ductile material and they are brittle that possess high strength-to-weight ratio, and able to increase the load capacity of a structure. However, in this study, the CFRP rod is used only at the joint with specific length and it is located vertically, horizontally, and diagonally to increase capacity of joints during movement of frame. The diagonal arrangement of the CFRP improved the shear strength, flexibility, and ductility of the frames since joint able to deform without cracks occurrence in high amount of applied cyclic force. In addition, CFRP has high elasticity modulus compared to steel which lead to enhance the elastic deformation and ductility of frame.

\section{Strains in concrete}

Electrical-resistance strain gauges were placed on the concrete along the frames to observe the strain variation during loading in experimental tests. The results indicated that an increase of the strain in concrete is approximately proportional to the increase of imposed lateral load. Furthermore, the concrete strain at the top zones of the column and joint area is higher. The maximum compressive strain recorded for RCF is $1150 \mu \varepsilon$ which occurred at the left joint of the frame. Nonetheless, the maximum compressive strain recorded for RC-CFRP is $618 \mu \varepsilon$ which observed in at the left joint. Meanwhile, the strain record for bare UHPC is $78 \mu \varepsilon$ and a strain of $41 \mu \varepsilon$ is recorded for BU-CFRP both in the upper side of the column. All frames reached to their ultimate failure load after excessive cracking patterns were observed along the span of the tested frames. The results demonstrated that strain value is smaller in the frame specimen with embedded CFRP in the joints compared to bare frames, as shown in Fig. 16.

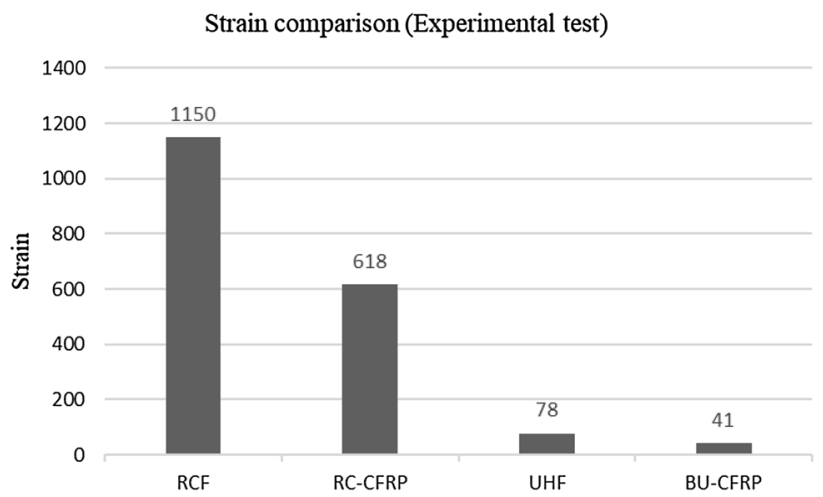

Fig. 16 Experimental test strain comparison of the frames
Table 4 Comparison between $\mathrm{UHF}$ and BU-CFRP

\begin{tabular}{llllll}
\hline Frame label & Max force $(\mathrm{kN})$ & $\begin{array}{l}\text { Max displace- } \\
\text { ment }(\mathrm{mm})\end{array}$ & Ductility & Stiffness & Energy dissipation \\
\hline UHF & 55 & 60 & 1.26 & 0.9 & $47,145.1$ \\
BU-CFRP & 61 & 57 & 2.25 & 1 & 49,400 \\
Increase (\%) & $11 \%$ & $5 \%$ & $78 \%$ & $11 \%$ & $4.80 \%$ \\
\hline
\end{tabular}




\section{Numerical modeling and finite-element analysis}

Numerical analysis was conducted to investigate and verify the effect of lateral load on the embedded CFRP bars in the beam-column joints in RC frame and UHPC frame. Figure 17 shows the steps taken for the numerical analysis.

ABAQUS software version 6.11 (2011) was used alongside the experimental test. Moreover, the cross-sectional measurements for FEM frame models were $2400 \mathrm{~mm}$, $1800 \mathrm{~mm}$, and $200 \mathrm{~mm}$ for the column height, beam length, and depth, respectively. The material properties for steel and CFRP are presented in Tables 1 and 2.

To damage analysis of concrete sections through finiteelement method, the damage plasticity parameters are defined for concrete, as depicted in Table 5. In addition, the mechanical properties of UHPC with $2 \%$ steel fiber which used for modeling of UHPC frame are presented in Table 6.

The concrete material properties for both experiment and numerical are considered as the same. Figure 18 shows the numerical model geometry.

In this study, three components were used, concrete, steel, and CFRP.

Evaluate the performance of embedded CFRP in joints with different concrete mixture (conventional \&UHPC)

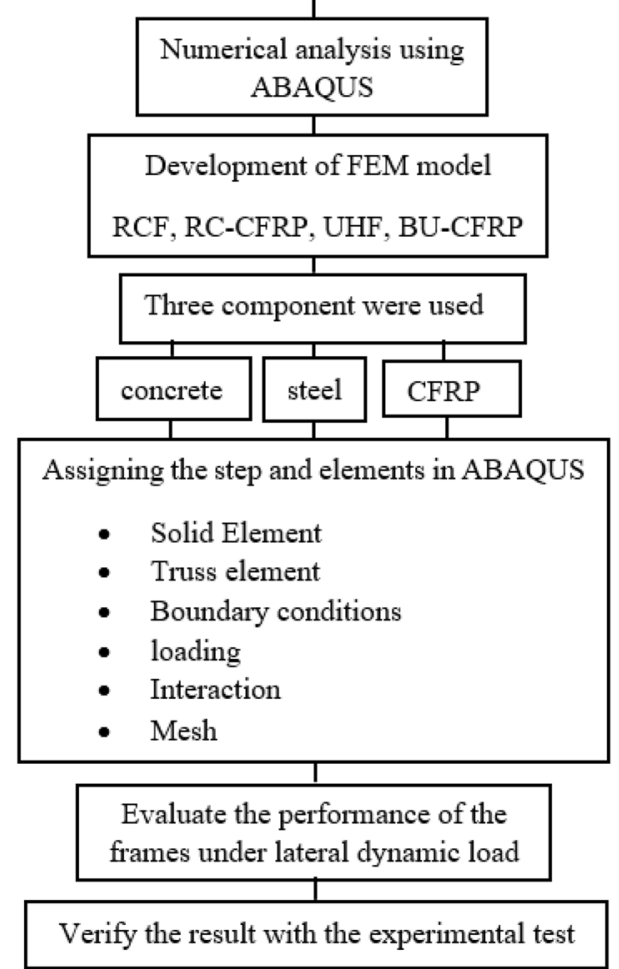

Fig. 17 Numerical study flowchart
The steel rebars' reinforcement is modeled as three dimensional truss elements. Three-dimensional two nodes first-order truss element (T3D2) is used to model the CFRPreinforcing bars in the FE model of the concrete frames.

Solid element is used for linear analysis complex nonlinear related to contact, plasticity, and large deformation. Three-dimensional eight-node first-order fully integration continuum element (C3D8) is used to model the concrete frames.

The boundary condition for the 3D solid-element frame was defined at the supports as Encastere, as shown in Fig. 19. The encastre boundary condition constrains all active structural degrees of freedom in the frame after the part is meshed and the job is created. This constraint will be applied to all the nodes that occupy the frame.

Moreover, the type of mesh used in this model was hexahedron-structured element, as demonstrated in Fig. 20. The different mesh size and mesh patterns for UHPC frame equipped with CFRP reinforcement in the joints have been implemented to capture the effect and performance of CFRP in UHPC frame and get a clearer result through choosing smaller mesh.

Apart from that, the interaction between CFRP and surrounding concrete in the FE model is considered as a perfect bond. Truss elements are used to symbolize the embedded CFRP bars within the host solid-element concrete frame. Furthermore, the solid element with embedded reinforcement is assumed to be a perfect bond only at the embedded nodes. Hence, if the embedded element had nodes at the edge of the host element, the reinforcement became free within the host element. If multiple nodes are used with the host element, the perfect bond is assumed to be true.

\section{Numerical result of RCF and RC-CFRP}

The comparison between bare frame and CFRP frame is shown in Fig. 21. The maximum load capacity for RCF was $69 \mathrm{kN}$ with maximum displacement of $71 \mathrm{~mm}$. Furthermore, the load-displacement relation for the frame with the embedded CFRP in the joints RC-CFRP had maximum load of $85 \mathrm{kN}$ and maximum displacement of $150 \mathrm{~mm}$. This frame demonstrated flexibility and great load capacity. In addition, the result showed that the load capacity for the frame with embedded CFRP increased by $23 \%$ together with its flexibility. Moreover, the RC-CFRP frame sustained less damage in tension and compression compared to RCF.

\section{Numerical result of UHF and BU-CFRP}

A comparison between UHF and BU-CFRP is illustrated in Fig. 22. Absolute maximum load for the bare 
Table 5 Material property of CDP model concrete class B50 (Nagy et al. 2010)

\begin{tabular}{|c|c|c|c|}
\hline \multirow{2}{*}{$\frac{\text { Materials parameters }}{\text { Concrete elasticity }}$} & \multicolumn{3}{|l|}{ Parameter } \\
\hline & & $\beta$ & 38 \\
\hline & & & 1 \\
\hline$E(\mathrm{GPA})$ & 19.7 & $f=f b_{0} / f \mathrm{c}$ & 1.12 \\
\hline$v$ & 0.19 & $\gamma$ & 0.67 \\
\hline \multicolumn{2}{|c|}{ Concrete compression hardening } & \multicolumn{2}{|c|}{ Concrete compression damage } \\
\hline Stress (Mpa) & Crushing strain & Damage $C\{-\}$ & Crushing strain $\{-\}$ \\
\hline 15 & 0 & 0 & 0 \\
\hline 20.197804 & $7.47307 \mathrm{E}-005$ & 0 & $7.47307 \mathrm{E}-005$ \\
\hline 30.000609 & $9.88479 \mathrm{E}-005$ & 0 & $9.88479 \mathrm{E}-005$ \\
\hline 40.303781 & 0.000154123 & 0 & 0.000154123 \\
\hline 50.007692 & 0.000761538 & 0 & 0.000761538 \\
\hline 40.23609 & 0.002557559 & 0.195402 & 0.002557559 \\
\hline 20.23609 & 0.002557559 & 0.596382 & 0.005675431 \\
\hline 5.257557 & 0.002557559 & 0.894865 & 0.011733119 \\
\hline \multicolumn{2}{|c|}{ Concrete tension stiffening } & \multicolumn{2}{|c|}{ Concrete tension damage } \\
\hline Stress (Mpa) & Crushing strain & Damage $C\{-\}$ & Crushing strain $\{-\}$ \\
\hline 1.99893 & 0 & 0 & 0 \\
\hline 2.842 & $3.333 \mathrm{E}-005$ & 0 & $3.333 \mathrm{E}-005$ \\
\hline 1.86981 & 0.000160427 & 0.406411 & 0.000160427 \\
\hline 0.862723 & 0.000279763 & 0.69638 & 0.000279763 \\
\hline 0.226254 & $0.0003 \backslash 68$ & 0.920389 & 0.000684593 \\
\hline 0.056576 & 0.00108673 & 0.980093 & 0.00108673 \\
\hline
\end{tabular}

Table 6 Mechanical properties of UHPC with 2\% steel fiber (Dura Technology (Sdn. Bhd)

\begin{tabular}{ll}
\hline Parameter & Value \\
\hline$f$ ck (Mpa) & 170 \\
Density $\left(\right.$ ton $\left./ \mathrm{mm}^{3}\right)$ & $2.5 \mathrm{E}-009$ \\
Modulus of elasticity $\left(\mathrm{N} / \mathrm{mm}^{2}\right)$ & 45,000 \\
Poisson's ratio $v$ & 0.2 \\
Dilation angle & 15 \\
Eccentricity & 0.1 \\
$f b o / f c 0$ & 1.16 \\
$K$ & 0.667 \\
Viscosity parameter & 0.01 \\
\hline
\end{tabular}

ultra-high-performance concrete UHF under cyclic load was $23 \mathrm{kN}$ with maximum displacement of $33 \mathrm{~mm}$. Meanwhile, the maximum load for ultra-high-performance concrete with embedded CFRP in joints BU-CFRP was $47 \mathrm{kN}$ and its maximum displacement was $24 \mathrm{~mm}$. The result indicated that the load capacity improved by $100 \%$ for the frame with CFRP in the joints compared to bare frame.

\section{Ductility, stiffness and energy dissipation}

The skeleton graph of the RCF and RC-CFRP is illustrated in Fig. 23. It was observed that the embedded CFRP in the joints increased the lateral load resistance of the RC-CFRP frame. In addition, the ductility and stiffness of the frame increased by $77 \%$ and $13 \%$, respectively. In addition, the energy dispassion increased by $200 \%$ compared to RCF without CFRP in the joints.

Moving on, the comparison between the UHF and BUCFRP skeleton graph is shown Fig. 24. The ductility of the frame with the embedded CFRP increased by $5 \%$, while the stiffness improved by $63 \%$ and energy dissipation increased by $200 \%$.

\section{Stresses distributions in RCF and RC-CFRP}

The stress distributions in RCF and RC-CFRP frames are presented in Fig. 25. The figure also illustrates the stress distribution on the concrete for RCF frame. It was observed that the stress increased in the beam-column joint of the frame without embedded CFRP. In contrast, the stress decreased by $20 \%$ in RC-CFRP, as shown in Fig. 26. It can, therefore, be concurred that the embedded CFRP assisted in reducing the 


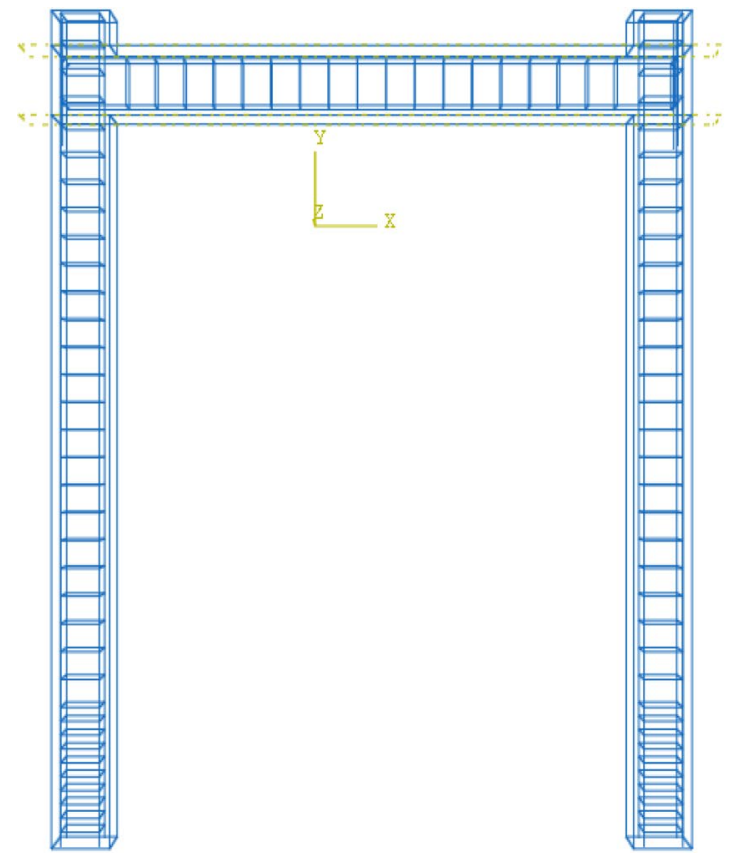

(a)

Fig. 18 FE model: a RCF FE model, b RC-CFRP model

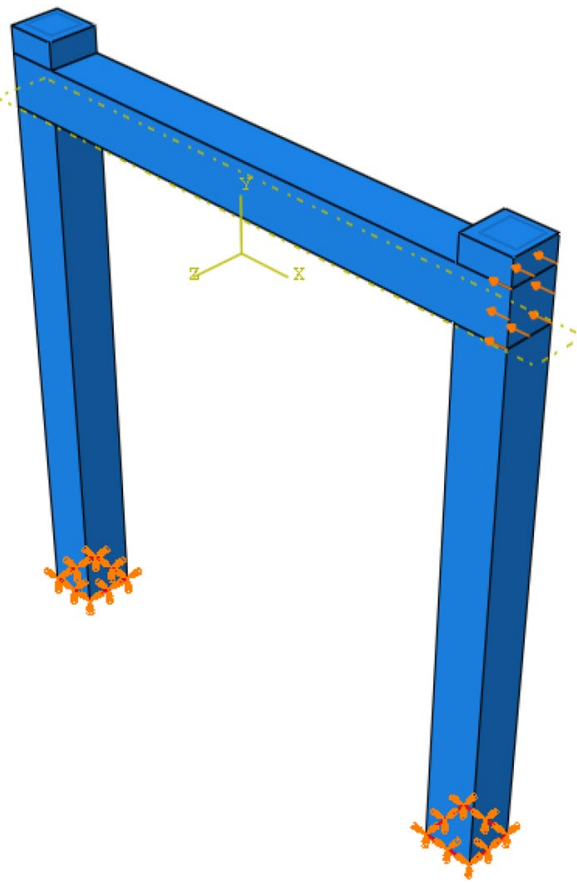

Fig. 19 Boundary condition and loading

stress in the concrete by sustaining a big portion of stress, lowering the effect on the concrete.

Moreover, the stress distributions on the steel reinforcement in RCF and RC-CFRP along with the embedded CFRP

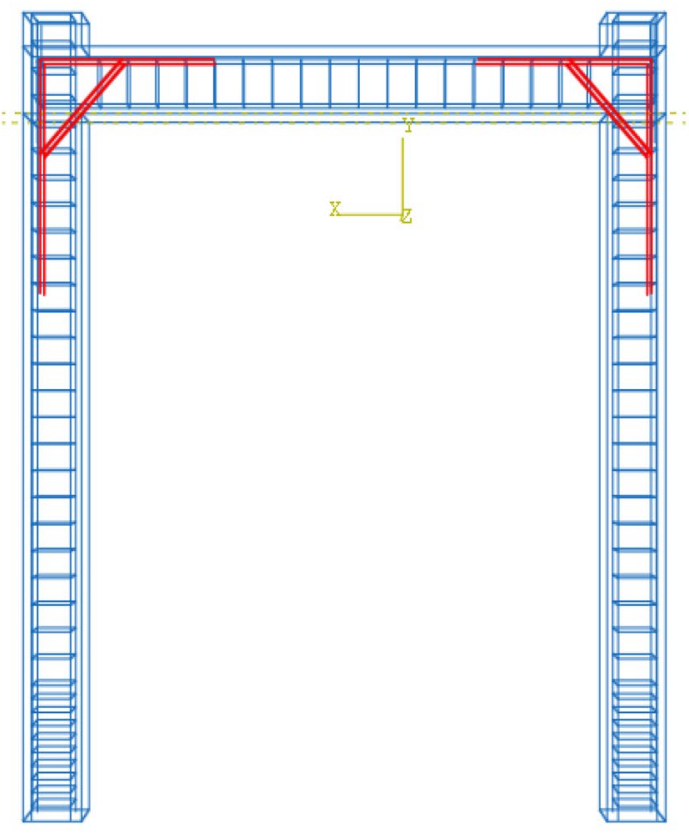

(b)

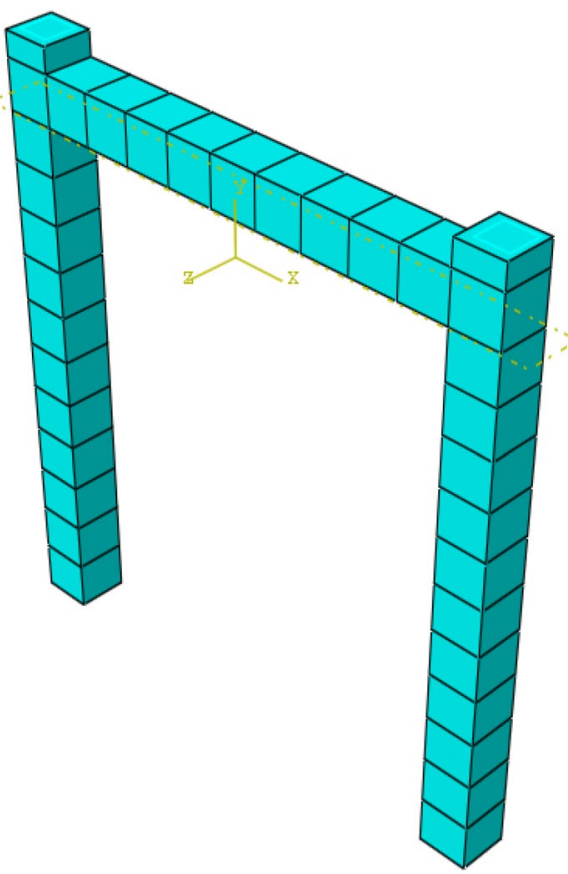

Fig. 20 Frame meshing

in RC-CFRP are shown in Figs. 27, 28, and 29. The steel reinforcement in RCF sustained $37 \mathrm{Mpa}$ of stress and a significant deformation which will had affected the concrete. Meanwhile, the steel reinforcement in RC-CFRP sustained 


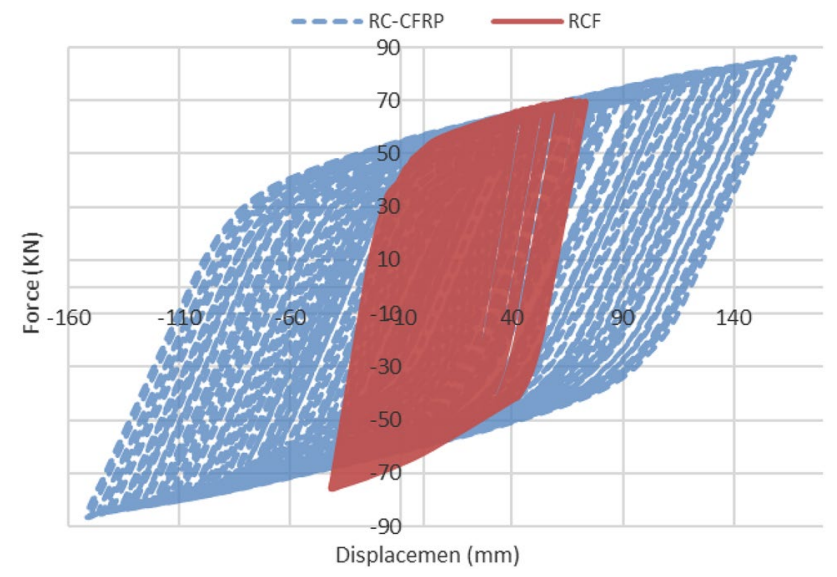

Fig. 21 Comparison between RCF and RC-CFRP hysteresis loop

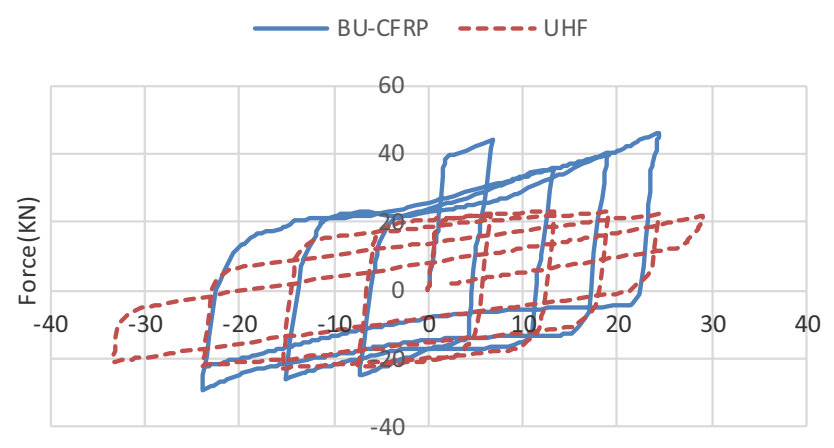

Dis placement $(\mathrm{mm})$

Fig. 22 Hysteresis loop UHF vs BU-CFRP

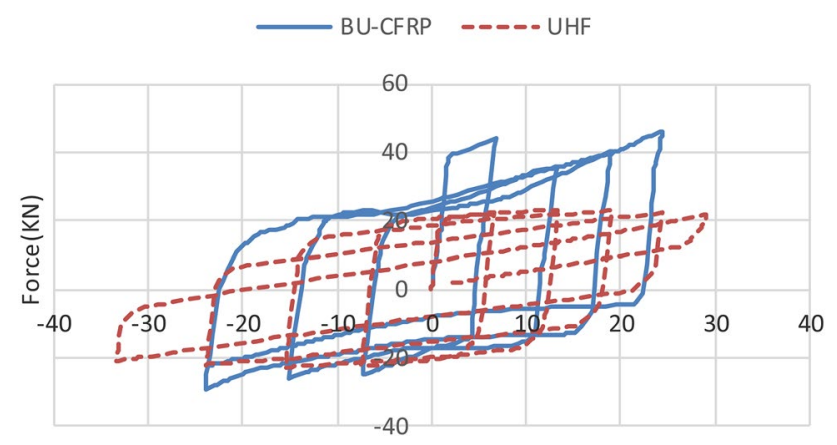

Displacement $(\mathrm{mm})$

Fig. 23 RCF and RC-CFRP skeleton graph

an equal amount of stress as the RCF without any noticeable deformation. This was because the stresses were distributed with the embedded CFRP that was reinforced in the joints. Therefore, CFRP was important in reducing the stress in the concrete and the steel rebars. This proved the effectiveness of embedded CFRP in the joints. Table 7 presents the

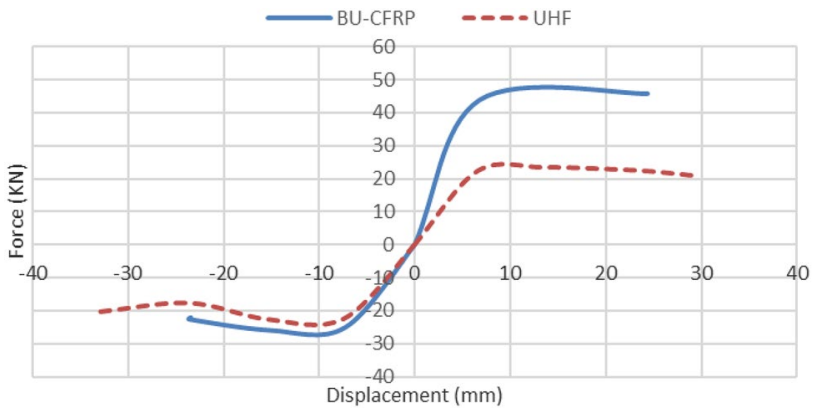

Fig. 24 UHF and BU-CFRP skeleton graph
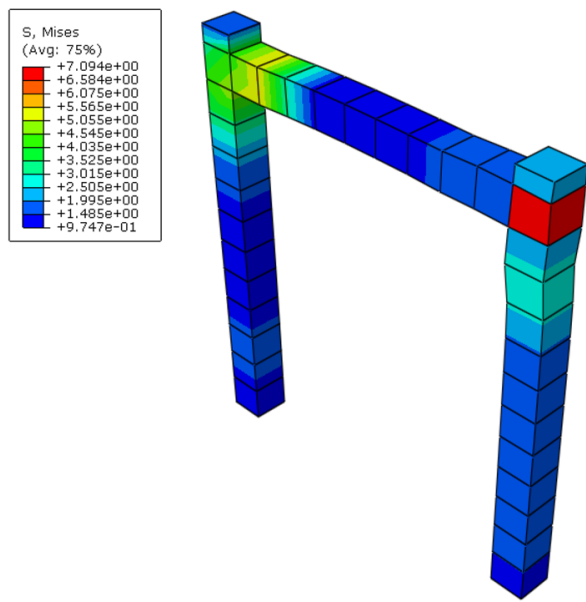

Fig. 25 Stress in RCF
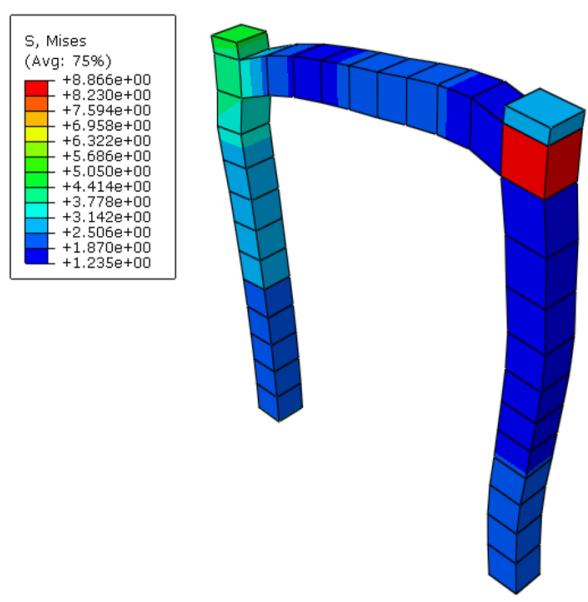

Fig. 26 Stress in RC-CFRP

maximum principal stress values for RCF and RC-CFRP frames. 

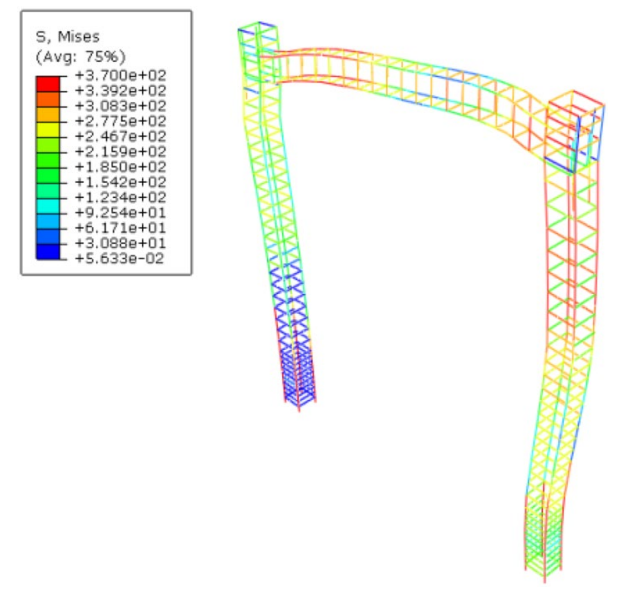

Fig. 27 Stress at steel for RCF
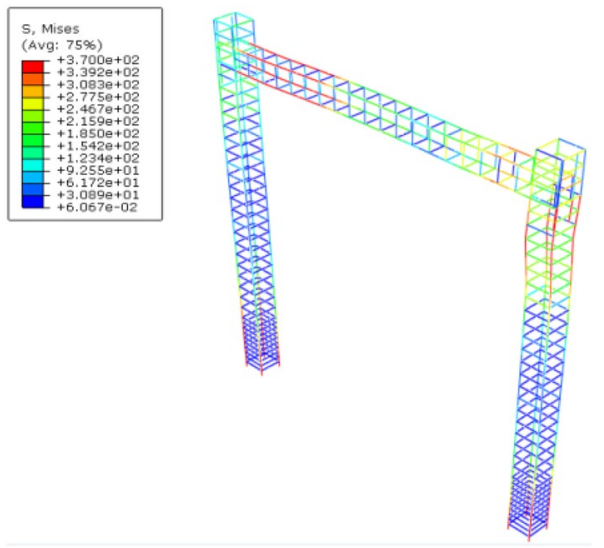

Fig. 28 Stress at steel in RC-CFRP
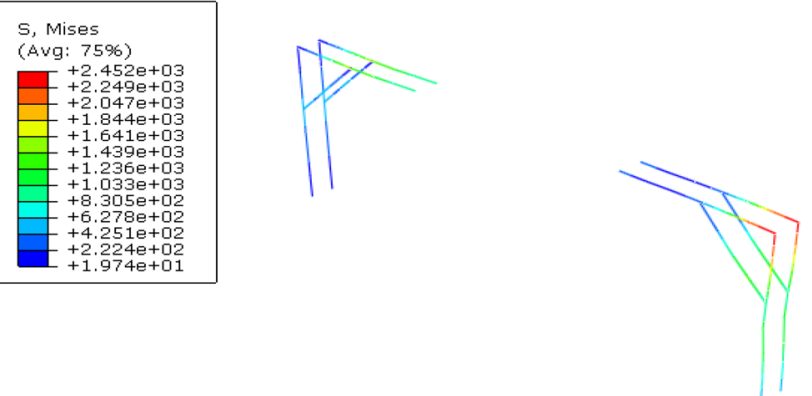

Fig. 29 Stress at the embedded CFRP

\section{Stresses distributions in UHF and BU-CFRP}

The stress distribution on the concrete for UHPC frames, UHF, and BU-CFRP is shown in Figs. 30 and 31. The stress raised noticeably at the joint and the beam span increased. Furthermore, the stresses in BU-CFRP with
Table 7 Maximum stress comparison RCF vs RC-CFRP

\begin{tabular}{lllll}
\hline Frame & $\begin{array}{l}\text { Stress in } \\
\text { concrete } \\
(\mathrm{Mpa})\end{array}$ & Reduction (\%) & $\begin{array}{l}\text { Stress in } \\
\text { steel (Mpa) }\end{array}$ & $\begin{array}{l}\text { Stress in } \\
\text { CFRP } \\
(\mathrm{Mpa})\end{array}$ \\
\hline RCF & 88.7 & - & 37 & - \\
RC-CFRP & 70.94 & $20 \%$ & 37 & 24.52 \\
\hline
\end{tabular}
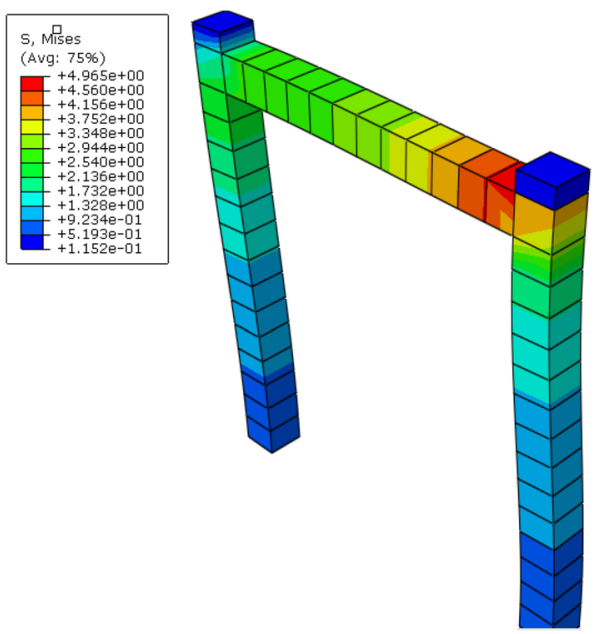

Fig. 30 Stress in UHF
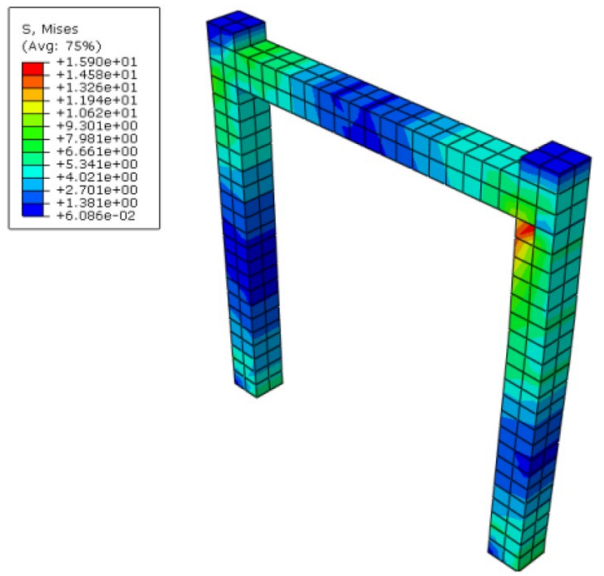

Fig. 31 Stress at BU-CFRP

embedded CFRP reinforcement in the joint reduced by $68 \%$ compared to UHF. It is worth noting that the maximum stress was located at the inner side of the beam-column joint and the CFRP bars absorbed most of the stresses from the concrete. In addition, the maximum stress was 99.47 Mpa, as shown in Fig. 32. The CFRP proved to be able to reduce the stress in the UHPC by absorbing the 

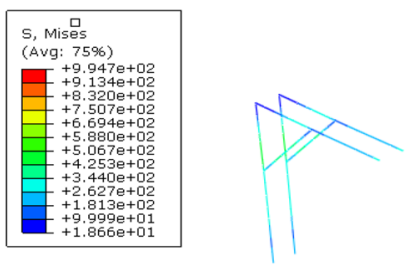

Fig. 32 Stress at the CFRP in BU-CFRP

Table 8 Maximum stress UHF vs BU-CFRP

\begin{tabular}{llll}
\hline Frame & $\begin{array}{l}\text { Stress (Mpa) in } \\
\text { concrete }\end{array}$ & Reduction $(\%)$ & $\begin{array}{l}\text { Stress in } \\
\text { CFRP } \\
(\mathrm{Mpa})\end{array}$ \\
\hline UHF & 49.65 & - & - \\
BU-CFRP & 15.9 & $68 \%$ & 99.47 \\
\hline
\end{tabular}

majority of the stresses. Table 8 presents the maximum principal stress values for UHF and BU-CFRP frames.

\section{Verification between the experimental and numerical results}

Since this study incorporated the use of experimental test and finite-element simulation, the comparison between them is reported in terms of maximum load and maximum displacement. The summaries of aforementioned comparison are presented in Table 9. As mentioned earlier, RC-CFRP frame and BU-CFRP frame were equipped with embedded CFRP in the joints, while RCF and UHF were bare frames. From the models (RCF, RC-CFRP, UHF, and BU-CFRP), the difference between the maximum load from the experiments and from finite-element simulation was $9 \%, 6 \%, 58 \%$, and $24 \%$, respectively. For UHF model, the maximum load difference was slightly altered by the damage properties of UHPC that were not defined in the FE model. Furthermore, the difference between the maximum displacement from the experiment and from the finite-element simulation was $21 \%, 76 \%, 45 \%$, and $57 \%$, respectively.

The difference between the finite-element simulation results and experimental testing results is due to:

1) Sliding in the support of concrete frames during the testing. While in the finite-element model, the frame supports are considered as perfect fixed conditions.

2) The condition and constitutive models for the concrete are assumed in perfect condition for numerical model; however, in the experimental test, the concrete quality might be less than the assumed perfect condition. In addition, the micro-cracks are neglected in numerical analysis.

In addition, it is observed that the FE result for RC-CFRP maximum load is $85 \mathrm{kN}$, while in the experiment, it was $80 \mathrm{kN}-6 \%$ difference.

By comparing the experimental test and numerical analysis results, it is observed that the hysteresis loops in the experimental test look different than the numerical simulation. The main reason is sliding of frame support during applying cyclic load which leads to moving of frame to the center position in the reverse cycles without applying any force. In addition, in the defined constitutive model, the behaviour of concrete in unloading condition is considered as perfect and softening action of concrete has been not considered. However, the real behaviour of concrete during unloading is different which led to different patterns for hysteresis results of frame subjected to cyclic load in numerical analysis and experiential testing.

Based on the results for both experimental test and finiteelement simulation, it was observed that the frame with the embedded CFRP bars in the beam-column joints is performed better in comparison with bare frames.

Table 9 Max load-displacement experiment test vs numerical analysis

\begin{tabular}{|c|c|c|c|c|c|c|}
\hline \multirow[t]{2}{*}{ Model's type } & \multirow{2}{*}{$\begin{array}{l}\text { Max load }(\mathrm{kN}) \\
\text { Experiment }\end{array}$} & \multirow{2}{*}{$\begin{array}{l}\text { Max load }(\mathrm{kN}) \\
\text { Numerical }\end{array}$} & \multirow[t]{2}{*}{ Difference (\%) } & \multirow{2}{*}{$\begin{array}{l}\text { Max-displacement }(\mathrm{kN}) \\
\text { Experiment }\end{array}$} & \multirow{2}{*}{$\begin{array}{l}\text { Max-displace- } \\
\text { ment (mm) } \\
\text { Numerical }\end{array}$} & \multirow[t]{2}{*}{$\begin{array}{l}\text { Difference } \\
(\%)\end{array}$} \\
\hline & & & & & & \\
\hline $\mathrm{RCF}$ & 63 & 69 & 9 & 90 & 71 & 21 \\
\hline RC-CFRP & 80 & 85 & 6 & 85 & 150 & 76 \\
\hline UHF & 55 & 23 & 58 & 60 & 33 & 45 \\
\hline BU-CFRP & 61 & 46 & 24 & 57 & 24 & 57 \\
\hline
\end{tabular}




\section{Conclusion}

In this study, a new design for the beam-column joints with embedded carbon fiber-reinforced polymer is proposed for reinforced concrete frame and ultra-high-performance concrete frame to mitigate the effect of dynamic load caused by earthquake. In addition, experimental test is conducted on the frames with embedded carbon fiber-reinforced polymer. This is to assess the seismic performance, functionality, and performance of the frames reinforced with embedded carbon fiber-reinforced polymer subjected to cyclic dynamic test:

1. The ductility behaviour, overall stiffness, and failure mechanism were enhanced in reinforced concrete frame with embedded carbon fiber-reinforced polymer and the ultra-high-performance concrete with embedded carbon fiber-reinforced polymer compared to bare frame.

2. The experimental result showed improvement in the performance of the frames that reinforced with embedded carbon fiber-reinforced polymer in the joints.

3. Ultra-high-performance concrete frame showed a poor performance against lateral dynamic load compared to conventional reinforced concrete frame, which led to the failure of experimental test and numerical test.

Apart from experimental test, numerical analysis was performed on the frames with embedded carbon fiber-reinforced polymer to evaluate and verify the performance of the reinforced carbon fiber-reinforced polymer in the frame joints. The results illustrated that the maximum lateral load, ductility. and stiffness resistance increased in frames that were equipped with embedded carbon fiber-reinforced polymer. In addition, there was a decrease of stress in both types of frames that were embedded with carbon fiber-reinforced polymer in the joints. There was a sound agreement between the experimental test and numerical analysis.

Acknowledgements This work received financial support from Universiti Putra Malaysia (UPM) under the Putra Grant Research Project, no. 9531200 . Their support is gratefully acknowledged.

Open Access This article is distributed under the terms of the Creative Commons Attribution 4.0 International License (http://creativeco mmons.org/licenses/by/4.0/), which permits unrestricted use, distribution, and reproduction in any medium, provided you give appropriate credit to the original author(s) and the source, provide a link to the Creative Commons license, and indicate if changes were made.

\section{References}

ABAQUS Version (2011) 6.11 Documentation. Dassault Systemes Simulia Corp., Providence, RI, USA

Antonopoulos CP, Triantafillou TC (2003) Experimental investigation of FRP-strengthened RC beam-column joints. J Compos Constr 7(1):39-50
ATC (1996) ATC 40, seismic evaluation and retrofit of concrete buildings. ApplTechnolCounc 1:334

Beydokhty EZ, Shariatmadar H (2016) Behavior of damaged exterior RC beam-column joints strengthened by CFRP composites. Lat Am J Solids Struct 13:880-897

Bischof P, Suter R, Chatzi E, Lestuzzi P (2014) On the use of CFRP sheets for the seismic retrofitting of masonry walls and the influence of mechanical anchorage. Polymers 6(7):1972-1998. https:// doi.org/10.3390/polym6071972

Cheng L (2005) Development of a steel-free FRP-concrete slab-on-girder modular bridge system. University of California, San Diego

Çopur A, Guler S, Ozalp F, Aydogan M (2013) Performance of CFRP wrapped UHPC columns under axial compression. Int J Chem Environ Biol Sci 1(1):57-60

Dan S, Bob C, Badea C, Dan D, Florescu C, Cotoarba L, Gruin A (2018) Carbon fiber reinforced polymers used for strengthening of existing reinforced concrete structures. Mater Plast 55(January):536-540

Ei-hacha R, Rizkalla SH (2005) Near-surface-mounted fiber-reinforced polymer reinforcements for flexural strengthening of concrete structures. ACI Struct J 101:717-726

El-Zeadani M, Saifulnaz MR, Hejazi F, Amran YM, Jaafar MS, Alyousef R, Alrshoudi F (2019) Mechanics-based approach for predicting the short-term deflection of CFRP plated RC beams. Compos Struct 225:111169

Erol G, Karadogan HF, Cili F (2008) Seismic strengthening of infilled RC frames by CFRP. In: th The 14 World Conference on earthquake engineering october 12-17, 2008, Beijing, China SEISMIC

Esmaeeli E, Barros JO, Sena-Cruz J, Fasan L, Li Prizzi FR, Melo J, Varum H (2015) Retrofitting of interior RC beam-column joints using CFRP strengthened SHCC: cast-in-place solution. Compos Struct 122:456-467. https://doi.org/10.1016/j.compstruct .2014 .12 .012

Ghosh KK (2002) Seismic upgrade with CFRP of RC columns containing lap spliced rebars in plastic hinge region. University of Toronto, Toronto. https://doi.org/10.16953/deusbed.74839

Godat A, Hady AL, Chaallal O, Neale KW (2012) Bond behavior of the ETS FRP bar shear-strengthening method. J Compos Constr 16:529-539. https://doi.org/10.1061/(ASCE)CC.1943-5614.00002 80

Ha GJ, Cho CG, Kang HW, Feo L (2013) Seismic improvement of RC beam-column joints using hexagonal CFRP bars combined with CFRP sheets. Compos Struct 95:464-470. https://doi.org/10.1016/j. compstruct.2012.08.022

Kim Y (2006) Strengthening concrete structures with prestressed CFRP sheets: laboratory and numerical investigations to field application. Queen's University, Kingston

Kumar V, Singh R, Quraishi MA (2013) A study on corrosion of reinforcement in concrete and effect of inhibitor on service life of RCC. J Mater Environ Sci 4(5):726-731

Le-Trung K, Lee K, Lee J, Lee DH, Woo S (2010) Experimental study of RC beam-column joints strengthened using CFRP composites. Compos B Eng 41(1):76-85. https://doi.org/10.1016/j.composites b.2009.06.005

Liu S, Sun W, Jing H, Dong Z (2019) Debonding detection and monitoring for CFRP reinforced concrete beams using piezoceramic sensors. Materials 12:2150

Mutsuyoshi H, Hai ND, Aravinthan T, Manalo A (2011) Experimental investigation of HFRP composite beams. Am Concr Inst 275:34-43. https://doi.org/10.14359/51682423

Nagy N, Mohamed M, Boot JC (2010) Nonlinear numerical modelling for the effects of surface explosions on buried reinforced concrete structures. Geomech Eng 2(1):1-18

Nor NM, Boestamam MHA, Yusof MA et al (2013) Carbon fiber reinforced polymer (CFRP) as reinforcement for concrete beam. Int J Emerg Technol Adv Eng 3(2):6-10 
Ohu RB (2012) Flexural response of reinforced concrete beams with embedded CFRP plates. Universiti Putra Malaysia, Seri Kembangan

Potluri R, Ketha KK (2015) Comparison between GFRP and CFRP composite power take-off shaft in helicopters for prescribed torque and geometrical constraints. J Mater Sci Mech Eng 2(3): 214-219. https ://www.krishisanskriti.org/vol_image/08Jul201509073306\%20\%20 \%20\%20\%20\%20\%20\%20Rakesh\%20P\%201\%20\%20\%20\%20\%20 $\% 20 \% 20 \% 20 \% 20 \% 20 \% 20 \% 20214-219$.pdf. Accessed April-June 2015

Qin R, Lau D, Tam LH, Liu T, Zou D, Zhou A (2019) Experimental investigation on interfacial defect criticality of FRP-confined concrete columns. Sensors (Switzerland) 19(3):1-14. https://doi. org/10.3390/s 19030468

Quiertant M, Ferrier E, Chataigner S, Sadone R, Quiertant M, Paris-est U (2012) Anchoring FRP laminates for the seismic strengthening of RC columns. In: International Conference on Concrete Repair, Rehabilitation and Retrofittin

Sharbatdar M-K (2003) Concrete columns and beams reinforced with FRP bars and grids under monotonic and reversed cyclic loading. University of Ottawa, Ottawa

Vaghani M, Vasanwala S, Desai K (2015) Performance of RC beam column connections subjected to cyclic loading. IOSR J Mech Civil Eng 12(2):2320-2334. https://doi.org/10.9790/1684-12274853

Wang L, Xuan W, Zhang Y, Cong S, Liu F, Gao Q, Chen H (2016) Experimental and numerical research on seismic performance of earthquake-damaged RC frame strengthened with CFRP sheets. Adv Mater Sci Eng 2016:1-11

Wang X, Qi Y, Sun Y, Xie Z, Liu W (2019) Compressive behavior of composite concrete columns with encased FRP confined concrete cores. Sensors (Basel, Switzerland) 19(8):1792. https://doi. org/10.3390/s19081792

Zhang H, Xu X (2019) Comparative analysis of dynamic characteristics of concrete frames reinforced with GFRP Bars and CFRP Bars. In: IOP Conference Series: earth and environmental science (vol 267). https://doi.org/10.1088/1755-1315/267/4/042115

Zhang K, Tang W, Fu K (2018) Modeling of dynamic behavior of carbon fiber-reinforced polymer (CFRP) composite under X-ray radiation. Materials 11(1):143. https://doi.org/10.3390/ma11010143

Zhou Y, Zhou Y, Zheng Y (2019) Performance of CFRP Anchors under dynamic loading. In IOP Conference Series: earth and environmental science (vol 304, p 032080). https://doi.org/10.1088/1755$1315 / 304 / 3 / 032080$

Publisher's Note Springer Nature remains neutral with regard to jurisdictional claims in published maps and institutional affiliations. 